\title{
Is Listeria innocua 2030c, a tetracycline-resistant strain, a suitable marker for replacing $L$. monocytogenes in challenge studies with cold-smoked fish?
}

\author{
Manuela Vaz-Velho ${ }^{\text {a,c,* }}$, Fátima Fonseca ${ }^{\text {a }}$, Manuela Silva ${ }^{a}$, Paul Gibbs ${ }^{\text {a,b }}$ \\ ${ }^{a}$ Escola Superior de Biotecnologia, Universidade Católica Portuguesa, Rua Dr. António Bernardino de Almeida, 4200 Porto, Portugal \\ ${ }^{\mathrm{b}}$ Leatherhead Food Research Association, Surrey, UK \\ ${ }^{\mathrm{c}}$ Escola Superior de Tecnologia e Gestão, Instituto Politécnico de Viana do Castelo, Portugal
}

Keywords: Carnobacterium spp.; Listeria spp.; Ozone

\begin{abstract}
The suitability of Listeria innocua 2030c, a tetracycline-resistant strain, to be used as an indicator for replacing Listeria monocytogenes in challenge studies with cold-smoked fish was ascertained. L. innocua 2030c was compared to serovars 4b and $1 / 2 \mathrm{c}$ of L. monocytogenes, the major types isolated from Portuguese cold-smoked fish products. Growth curves at $30^{\circ} \mathrm{C}$, growth/survival patterns at $30^{\circ} \mathrm{C}$ under exposure to different times and concentrations of ozone and sensitivity to Carnobacterium divergens V41 and C. piscicola V1 and their bacteriocins V41 and V1, were determined. No important differences between L. innocua $2030 \mathrm{c}$ and L. monocytogenes $4 \mathrm{~b}$ and $1 / 2 \mathrm{c}$ were found, therefore L. innocua 2030c can be considered a suitable indicator for replacing those L. monocytogenes strains in challenge studies. (C) 2001 Elsevier Science Ltd. All rights reserved.
\end{abstract}

\section{Introduction}

Listeria monocytogenes is a pathogenic bacterium for immuno-compromised people and foetuses of pregnant women. Because of this pathogenicity it generally would not be possible to conduct actual challenge studies under any conditions other than a laboratorysimulated process. As challenge studies with inoculated fish for cold-smoking purposes were intended to be performed in a pilot plant rather than in a research laboratory it was necessary to replace L. monocytogenes by a non-pathogenic strain, and to ensure that it behaved equally to the pathogen under the same processing conditions.

Listeria innocua strains resistant to the antibiotics chloramphenicol and erythromycin have been used with success as indicators for evaluation of the lethality of

\footnotetext{
${ }^{*}$ Corresponding author. Tel.: +351-22-5580043; fax: +351-225090351.

E-mail address: manuela@esb.ucp.pt (M. Vaz-Velho).
}

thermal processes with respect to $L$. monocytogenes (Foegeding \& Stanley, 1991).

Treatment of fish with ozone and application of bacteriocins are potential means of reducing $L$. monocytogenes levels in cold-smoked fish products. A suitable non-pathogenic marker should behave similarly to the pathogen L. monocytogenes when subjected to the same treatments while simultaneously being easily identified as non-natural cold-smoked fish flora. As all the strains of L. monocytogenes and L. innocua isolated from Portuguese cold-smoked fish were, until now, tetracyclinesensitive, Listeria innocua 2030c, a tetracycline-resistant strain, was chosen for this purpose.

For ascertaining the similarity of their behaviours, L. innocua $2030 \mathrm{c}$ was compared to serovars $4 \mathrm{~b}$ and $1 / 2 \mathrm{c}$ of $L$. monocytogenes, the major types isolated from Portuguese cold-smoked fish products. Growth curves at $30^{\circ} \mathrm{C}$, growth/survival patterns at $30^{\circ} \mathrm{C}$, and on exposure to different times and concentrations of ozone, and sensitivity to Carnobacterium divergens V41 and C. piscicola $\mathrm{V} 1$ and their bacteriocins $\mathrm{V} 41$ and $\mathrm{V} 1$ were determined. 


\section{Materials and methods}

\subsection{Ozone generation and measurements}

Ozone was produced by a domestic ozone generator model PR1 (TRIOZON, Spain) using atmospheric air as the source of oxygen. The ozonated air produced at a constant flow rate by the apparatus was passed via a silicone tube to a pump, and then to a plastic chamber of $26 \mathrm{dm}^{3}$ volume. The ozone in the air flow produced by the apparatus $\left(0.32 \mathrm{mg} \mathrm{l}^{-1}\right)$ was measured experimentally by the iodometric method as described Silva, Gibbs, and Kirby (1998). Also, the ozone concentration inside the chamber was calculated by a mass balance based on the total volume of the chamber, the air flow and the rate of production of ozone by the generator as described by Silva et al. (1998) (Fig. 1).

\section{Growth curves}

Pure cultures were grown in Tryptone soy yeast extract broth (TSB-YE) (Tryptone soy broth (Lab $\mathrm{M})+0.6 \% \mathrm{w} / \mathrm{v}$ yeast extract $(\mathrm{Lab} \mathrm{M})$ ) incubated at $30^{\circ} \mathrm{C}$. Curves were constructed using the drop counting technique (Miles \& Misra, 1938) on Tryptone soy agar (TSA-YE: TSB-YE $+1.2 \% \mathrm{w} / \mathrm{v}$ of agar) (Lab M) plates and incubated at $30^{\circ} \mathrm{C}$.

\subsection{Treatments}

\subsubsection{Ozone treatment}

L. innocua 2030c was obtained from the culture collection of the Public Health Laboratory Service (PHLS) in London. From overnight cultures of L. innocua 2030c $\left(10^{8-9} \mathrm{CFU} \mathrm{m} \mathrm{m}^{-1}\right)$ in TSB-YE (Lab M) serial decimal dilutions up to $10^{-9}$ were made in maximum recovery diluent (MRD) (Lab M). Cell suspensions were delivered onto pre-dried plates of TSA-YE (Lab M), using the drop counting technique (Miles \& Misra, 1938). Each plate was divided into four equal spaces and two separate $20 \mu \mathrm{l}$ aliquots were dropped in each space for each dilution. The inoculated plates were placed into an ozonation chamber and exposed to ozone for, respectively, 20, 40, 60, 80 and $90 \mathrm{~min}$. After treatment the plates were incubated at $30^{\circ} \mathrm{C}$ for $24 \mathrm{~h}$. This temperature was chosen because it is the temperature to be used in further experiments with cold-smoked fish previously inoculated with L. innocua 2030c. Results are the means of triplicate experiments.

\subsubsection{Bacteriocins}

L. innocua 2030c, L. monocytogenes $4 \mathrm{~b}$ and $1 / 2 \mathrm{c}$ strains were sent to École Nationale d'Ingénieurs des Techniques des Industries Agricole et Alimentaires (ENITIAA), Nantes, France. They were tested for their sensitivity to $C$. divergens $\mathrm{V} 41$ and $C$. piscicola $\mathrm{V} 1$ and their bacteriocins V41 and V1, following the protocol of Pilet et al. (1995) (Duffes, Corre, Leroi, Dousset, \& Boyaval, 2000).

\section{Results and discussion}

All the strains tested were equally sensitive to $C$. divergens V41 and $C$. piscicola V1 and their bacteriocins V41 and V1 (data not shown, reported by ENITIAA) therefore, L. innocua 2030c can be considered a suitable marker for replacing $L$. monocytogenes in experiments with application of these bacteriocin producers and/or their bacteriocins.

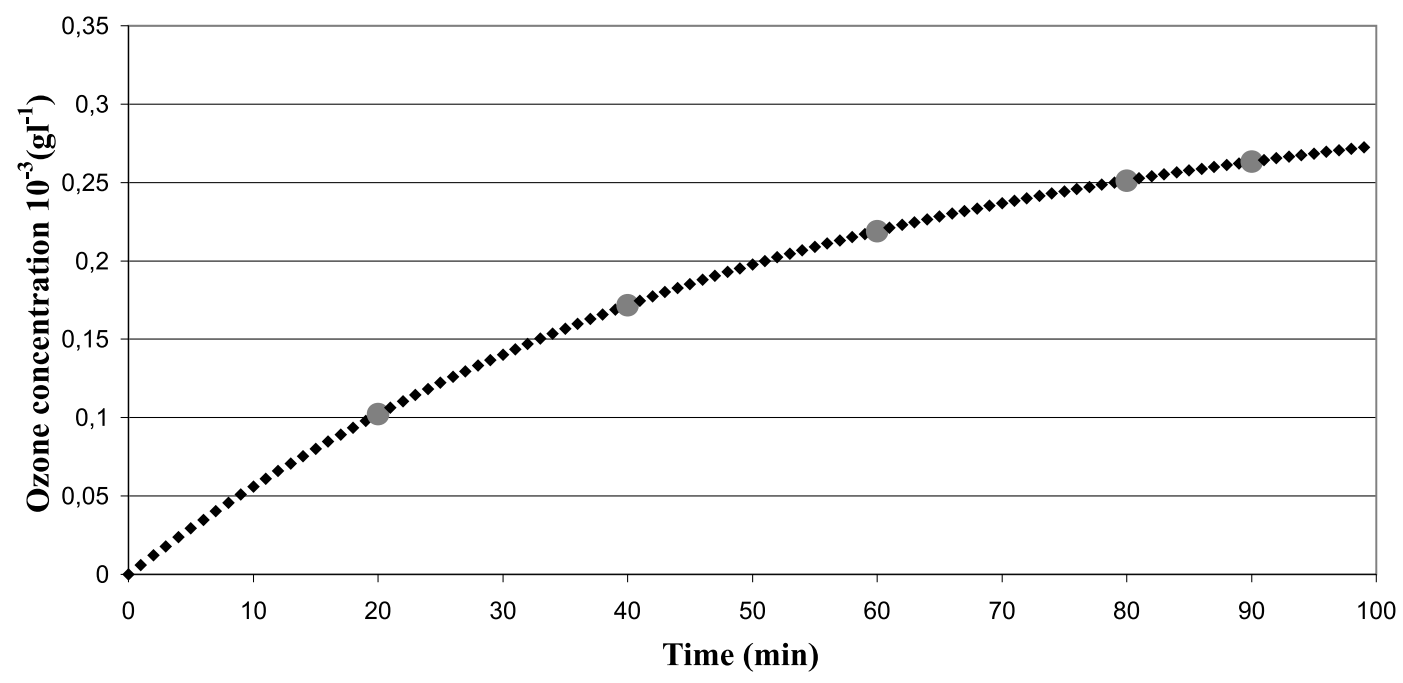

Fig. 1. Theoretical curve of ozone concentration in the air inside the desiccator. 
Growth curves at $30^{\circ} \mathrm{C}$ are shown in Fig. 2. A slightly longer lag phase was observed in $L$. innocua and $L$. monocytogenes $1 / 2 \mathrm{c}$ growth compared to $L$. monocytogenes $4 \mathrm{~b}$ strain. All the strains reached stationary growth phase with about 9.4-9.5 $\log \mathrm{CFU} \mathrm{ml}{ }^{-1}$ and the length of this phase was similar $(8-15 \mathrm{~h})$. L. monocytogenes $1 / 2 \mathrm{c}$ numbers then declined faster than $L$. innocua 2030c numbers and the latter declined faster than L. monocytogenes $4 \mathrm{~b}$ strain. Therefore, L. innocua $2030 \mathrm{c}$ can provide an additional margin of safety as an indicator organism with respect to $L$. monocytogenes $1 / 2 \mathrm{c}$ but not with respect to $L$. monocytogenes $4 \mathrm{~b}$ strain. Nevertheless, as differences in the number were ca. $0.5 \log \mathrm{CFU} \mathrm{ml} \mathrm{m}^{-1}$ they were considered not important for future applications on cold-smoking fish processing and storage experiments.
Exposure to gaseous ozone was shown to be effective in reducing bacterial levels. However, survival rates of the three strains were not linearly related to ozonation time (Fig. 3), the higher death rate (about $3 \mathrm{log}$ ) occurring during the first $20 \mathrm{~min}$ of ozone exposure and stabilising during the following $70 \mathrm{~min}$. Several other studies using ozone have also shown that death rate kinetics for a variety of bacteria and viruses exhibit a biphasic process over an extended time period (Broadwater, Hoehn, \& King, 1973; Ishikaki, Shinriki, \& Matsuyama, 1986; Silva et al., 1998). Silva et al. (1998) after testing three Gram-negative and two Gram-positive bacteria found that the higher death rate occurred after $15 \mathrm{~min}$ of exposure to ozone when the level of ozone inside the chamber was about $0.22 \times 10^{-3} \mathrm{~g}^{-1}$.

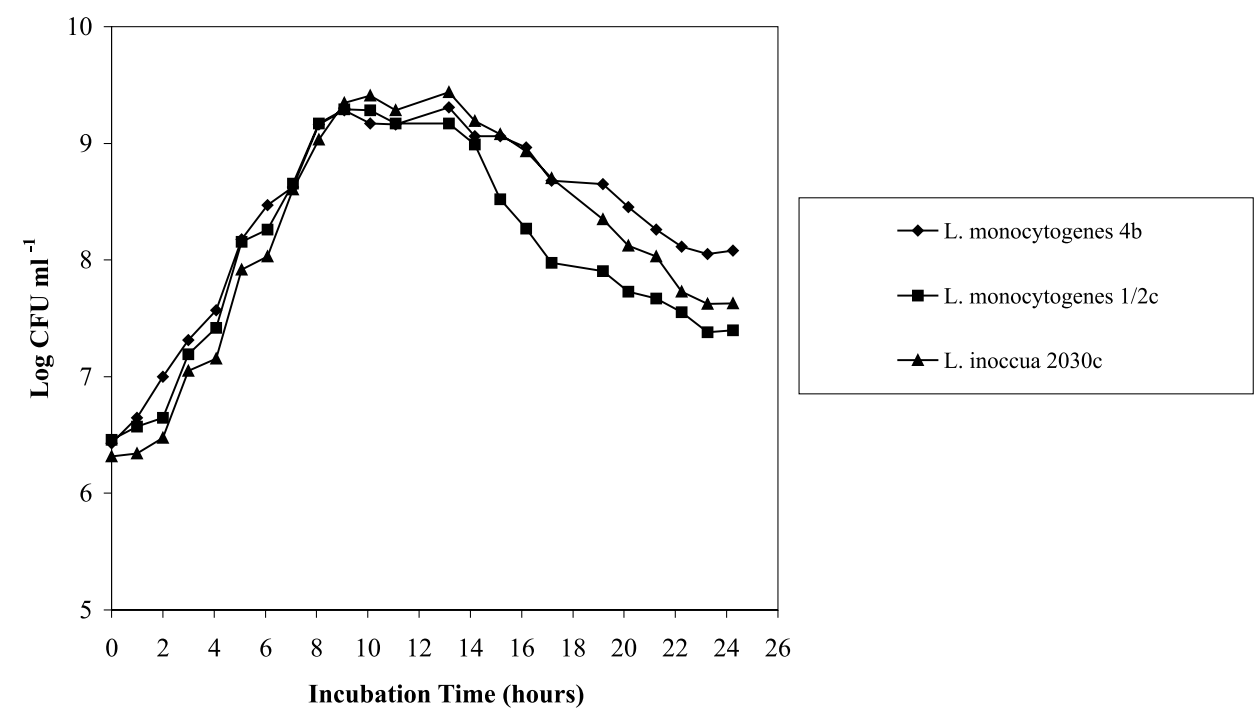

Fig. 2. Listeria spp. growth curves (at $\left.30^{\circ} \mathrm{C}\right)$.

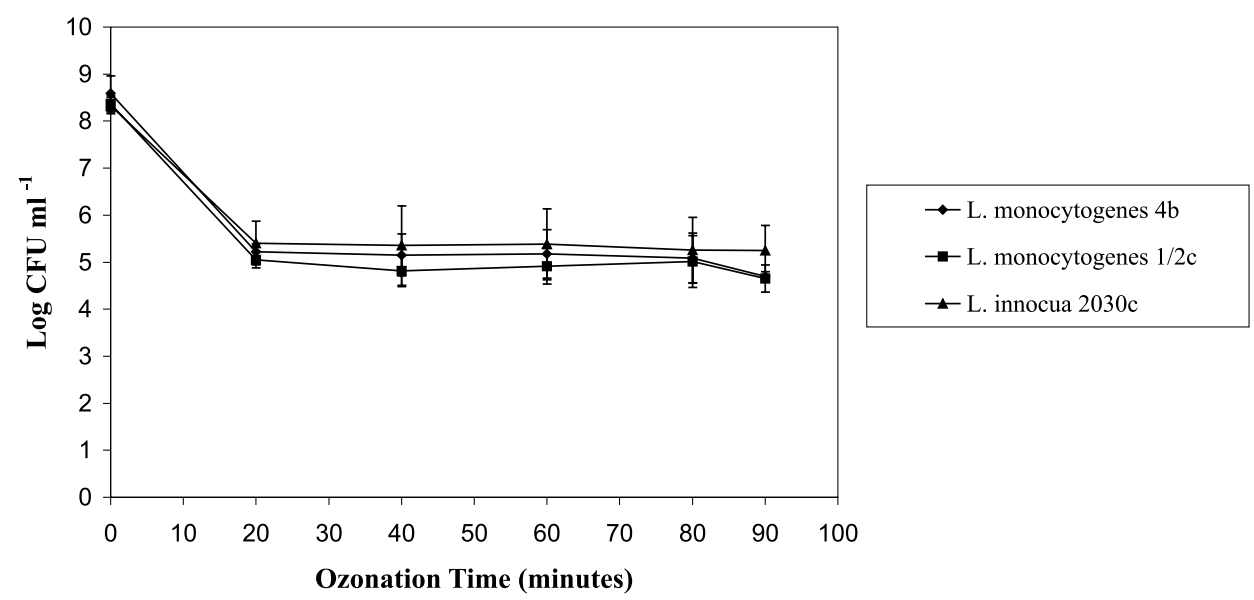

Fig. 3. Listeria spp. survivor curves during ozone exposure. 
The theoretical curve obtained for the ozone concentration in the air inside the chamber (Fig. 1) shows the ozone concentration after 20 and 90 min reaching, respectively, $0.1 \times 10^{-3}$ and $0.26 \times 10^{-3} \mathrm{~g}^{-1}$. A small decrease in the number of L. monocytogenes strains was noticeable after $90 \mathrm{~min}$ of ozone exposure whereas the number of $L$. innocua 2030c remained stable, therefore these differences will provide an additional margin of safety when using L. innocua 2030c as an indicator organism as it was more resistant to ozone than the L. monocytogenes strains.

Thus, for gaseous ozone treatments, the $20 \mathrm{~min}$, when the level of ozone reached $0.1 \times 10^{-3} \mathrm{~g}^{-1}$, can be considered the best time of exposure to reduce the number of all strains by about $3.5 \log \mathrm{CFU} \mathrm{m}{ }^{-1}$.

\section{Acknowledgements}

The authors gratefully acknowledge the EU FAIR CT95-1207 "Spoilage and Safety of Cold Smoked Fish" for financial support and Frédérique Duffes (from ENITIAA) for testing the sensitivity to bacteriocin producers $C$. divergens $\mathrm{V} 41, C$. piscicola $\mathrm{V} 1$ and their bacteriocins.

\section{References}

Broadwater, W. T., Hoehn, R. C., \& King, P. H. (1973). Sensitivity of three selected bacterial species to ozone. Applied Microbiology, 26, 391-393.

Duffes, F., Corre, C., Leroi, F., Dousset, X., \& Boyaval, P. (2000). Inhibition of Listeria monocytogenes by in situ produced and semipurified bacteriocins of Carnobacterium spp. on vacuumpacked, refrigerated cold-smoked salmon. Journal of Food Protection, 62(12), 1394-1403.

Foegeding, P. M., \& Stanley, N. W. (1991). Listeria innocua transformed with an antibiotic resistance plasmid as thermalresistant indicator for Listeria monocytogenes. Journal of Food Protection, 54(7), 519-523.

Ishikaki, K., Shinriki, N., \& Matsuyama, H. (1986). Inactivation of Bacillus spores by gaseous ozone. Journal of Applied Bacteriology, 60, 67-72.

Miles, A. A., \& Misra, S. S. (1938). The estimation of the bactericidal power of the blood. Journal of Hygiene, 38, 732-749.

Pilet, M. F., Dousset, X., Barre, R., Novel, G., Desmazeaud, M., \& Piard, J. C. (1995). Evidence of two bacteriocins produced by Carnobacterium piscicola and Carnobacterium divergens isolated from fish and active against Listeria monocytogenes. Journal of Food Protection, 58, 256-262.

Silva, M. V., Gibbs, P. A., \& Kirby, R. M. (1998). Sensorial and microbial effects of gaseous ozone on fresh scad (Trachurus trachurus). Journal of Applied Microbiology, 84, 802-810. 